\title{
Violence, Abuse and the Implications for Mental Health and Wellbeing of Security Operatives in the United Kingdom: The Invisible Problem
}

Dr Risto Talas, University of Portsmouth

Professor Mark Button, University of Portsmouth

Dr Mark Doyle, Solent University

Mr Jaideep Das, University of Portsmouth

\section{Abstract}

This paper addresses mental health and wellbeing among security operatives in the UK using a mixed methods approach of survey questionnaire and interviews. The survey questionnaires were designed using three hybrid surveys: Warwick-Edinburgh Mental Wellbeing Scale; The Post Traumatic Stress Disorder (PTSD) Checklist-Civilian Version (PCL-C); and CAGE-AID as a screen for substance misuse. The survey questionnaires were distributed with the support of the Security Industry Authority and the GMB Union and 754 completed surveys were returned and 15 interviews conducted. Results from the completed survey questionnaires show that $39.3 \%$ of the respondents were showing symptoms of PTSD and that many of the security operatives suffered varying degrees of verbal abuse and threats of physical violence with a number reporting acts of violence to themselves and other security operatives during the course of their employment. A key finding was the lack of provision of mental health and wellbeing services provided by the security companies to their employees and managers in general unable or unwilling to accept that some employees were suffering from poor mental health and wellbeing.

Key words: private security, violence, abuse, mental health, well being, post-traumatic stress disorder (PSTD)

\section{Introduction}

The private security industry during the last 50 years has transformed from a small niche sector to a global industry worth anything from $\$ 70$ to $\$ 244$ billion, employing millions with almost 600,000 working for the largest company in the world, G4S (Button, 2019). In the United Kingdom, which is the focus of this article, there are over 353,774 licensed security 
operatives and many more working in the sector who do not require a licence (Security Industry Authority, 2019a). Licensed security operatives in the UK are regulated by the Security Industry Authority (SIA) under the following main categories of licence: security officer, door supervisor, cash and valuables in transit, close protection, public space surveillance (CCTV) and keyholding. The regulator sets specific standards, including training, for each of the licence categories. Not all security operatives, however, require a licence as there are some exemptions. Security officers employed in-house do not require a licence and many government contracted out custody related services are regulated in a different way. The principal legislation regulating the sector, the 2001 Private Security Industry Act, gives no special powers to security operatives, although there are some specific sub-sectors with special powers, such as security officers working in courts and many operatives can derive de facto powers from their citizen rights, operating on private space and/or policing those engaged in an employment contract or equivalent (Button, 2007). Table 6, later in this paper, illustrates the main licensing categories the participants for this research were drawn from, with security guards and door supervisors accounting for over two thirds of the respondents.

Security operatives in the UK patrol public streets, shopping areas and transport hubs to name some; police the many night-time and entertainment venues; guard sensitive and important infra-structure such as government buildings, courts, social security officers, airports and ports and even military installations; and they transport valuables and prisoners to name some (Jones and Newburn, 1998; Noaks, 2000; Wakefield, 2003; Crawford, Lister, Blackburn and Burnett, 2005; Button, 2007; Hobbs, Hadfield, Lister and Winslow, 2005; White, 2012; Löfstrand, Loftus and Loader, 2016). The many roles undertaken by security operatives bring them into contact with the general public and staff, which often produces conflict leading to verbal abuse through to violent assault. In extreme cases some security operatives have even been killed in the course of their duties. For example in 2019, Tudor Simionov, was murdered trying to prevent gate crashers to a private party in Park Lane, London (The Guardian, 2019). Although such incidents are rare, they highlight the dangers of security work of which there are many lesser types of harms occurring on a much more regular basis with implications for the well being and mental health of security operatives. 
Private policing research has expanded significantly in recent years with many studies across the world highlighting the dangers, abuse and morale of security operatives (Rigakos, 2002; Pillay and Claase-Schutte, 2004; Button, 2007; Prenzler and Sarre, 2008; Ferguson, Prenzler, Sarre and De Caires, 2011; Leino, Selin, Summala and Virtanen, 2011; Hobbs et al, 2003; Nalla, Lim and Demirkol, 2015; Nalla and Cobbina, 2017; Nalla, Paek and Lim, 2017). Door supervisors have been explored in a number of studies highlighting significant dangers faced (Lister, Hobbs, Hall and Winlow, 2000; Winlow, 2001; Hobbs, O'Brien and Westmarland, 2007). Security officers in a variety of contexts have also been shown to experience violence and abuse, such as in policing public space (Button, 2007), retail outlets (Manzo, 2006) to name some. Such research has been focused upon specific organisational contexts and largescale surveys securing data on the extent of such violence across a sector have been rare.

There is therefore a gap in research exploring the extent of verbal and physical abuse security operatives experience and the toll this has on them. This study provides a unique insight on this issue by providing data on 754 security operatives by survey and 15 by interview in the UK, covering their experience of verbal abuse through to acts of violence and most significantly their levels of PTSD and state of their mental health. It will begin by exploring the literature on workplace trauma, it will then move on to outline the methodology used for this study. The paper will then explore the findings from this project, before concluding.

\section{Workplace trauma and the consequences}

Employment can be engaging and offer a range of rewarding experiences and achievement for individuals to develop professionally and personally. However, some employment is mixed with an element of risk and danger e.g. police, firefighters and healthcare. Recent research has demonstrated the importance of traumatic experiences in the development and maintenance of poor mental health (Doyle, Murphy and Shevlin, 2016). It has also been established that work related trauma can negatively impact quality of life and result in a range of Diagnostic and Statistical Manual-5 (DSM-5; American Psychiatric Association, 2013) related disorders including post-traumatic stress disorder, depression and anxiety related disorders (Kilpatrick, Resnick, Milanak, Miller, Keyes, et al. (2013). Current research shows that the scale and extent of physical and workplace violence has risen dramatically over 
recent years, specifically among prehospital emergency medical technicicians (Hosseinikia, Zarel, Kalyani and Tamantan, 2018). Research by Nienhaus, Drechsel-Schlund, Schambortski and Schablon (2016), Sweet (2017), Kvas and Seljak (2014) suggested that incidents of workplace violence are generally higher than reported. Previous research has explored the effects of trauma on the mental health of those who work in environments likely to result in trauma e.g. firefighters (Wagner, Heinrichs and Ehlert, 1998), police officers (Green, 2004) and emergency room personnel (Healy and Tyrell, 2011). However, the impact of workrelated trauma has yet to be explored in relation to multiple types of UK security operatives.

\section{Workplace violence}

Leino (2013) reported that among Finnish police officers and security guards in research conducted from 2002 to 2009, the most frequent form of violence was psychological violence: $63 \%$ of police officers and $39 \%$ of security guards respectively reported receiving insults at least once a month. Unarmed physical violence at least once a month among the same groups stood at $44 \%$ and $15 \%$ respectively. Furthermore, Leino (2013) also stated that among those who had sustained physical injuries, there was a tendency for increased alcohol consumption. Porter et al. (2015) observed the frequency and types of workplace violence against security operatives and found that $96 \%$ of the security guard sample had experienced at least one incident of physical assault during their tenure while working in security profession. According to SIA (Security Industry Authority, 2019b) "44 percent of door staff have needed hospital treatment after being assaulted at work." Door supervisors operate in a very risky environment. Injury and abuse are not a part of job description for security operatives, but they seem to be very common. Jenkins, Fisher and Hartley $(2012$, p63) consider workplace violence to be the "top security threat" and the reduction of violence against security operative has become a "top priority" for the British Security Industry Authority. Though not much is known about the extent of workplace victimization among security operatives (Leino, 2013; Vanheule, Declercq, Meganck and Desment, 2008; De Boer, Bakker, Syroit and Schaufeli, 2002) yet Button and Park (2009) conducted a broader research on assaults experienced by security guards. Many incidents go unreported as some victims appraise them as only minor; they see the exposure to workplace violence as part of their job (Kvas and Seljak,2014; Gates, Gillespie and Succop, 2011; European Agency for Safety and Health at Work, 2010; Vezyridis, Samoutis and Mavrikiou, 2014); are uncertain what kind of behaviours 
count as workplace violence (European Agency for Safety and Health at Work 2010; Waddington, Badger and Bull, 2005a; Waddington et al,.2005b); believe that reporting incidents would not change anything (Kvas and Seljak,2014; Vezyridis et al., 2014); and consider reporting as too complicated or too time consuming (Busby, 2015; Porter et al., 2015).

Research by Button (2007) observed that $52 \%$ of retail security guards within their sample experienced assaults once or twice a month and $17 \%$ once or twice a year. A qualitative study conducted in South Korea further in 2009 by Button confirms that few of the 20 retail security guards experienced monthly assaults at between $5 \%$ and $15 \%$, whereas the vast majority between $85 \%$ and $95 \%$, were spared from workplace violence suggesting some types of security professionals may be more vulnerable than others.

\section{Post-Traumatic Stress Disorder}

Post-Traumatic Stress Disorder or PTSD (American Psychiatric Association, 2013) is common with $5-10 \%$ possessing a diagnosis within Western countries (Kessler, Sonnega, Bromet, Hughes and Nelson, 1995). According to DSM-5 criteria, trauma involves actual or threatened harm including death, serious injury or sexual violence. It can also be experienced either directly or indirectly, witnessed, learned of or through repeated exposure to extreme details. Symptoms may include flashbacks, dissociative experiences, high levels of avoidance (cognitive and behavioural), negative cognitions and alterations to arousal including hypervigilance, exaggerated startled response and self-destructive behaviour. Individuals with PTSD are likely to self-medicate with alcohol or drugs (Button, 2019; Reynolds, Mezey, Chapman, Wheeler, Drummond et al., 2005). This has been theorized as a method of behavioural avoidance of the overwhelming emotions and sensory information and hyperarousal symptoms (Ehlers and Clark, 2000). The comorbidity between substance misuse and PTSD is substantial as reported in a review by Debell, Fear, Head, Batt-Rawden, Greenberg et al. (2014). Security operatives are likely to regularly experience and/or witness a range of threatened or actual physical harm in the course of their employment placing them at greater risk of developing PTSD (Button, 2019). 
Health and Safety in the Workplace

Harnois and Gabriel (2000) report on the nature of mental health and wellbeing issues in the workplace from the perspectives of the World Health Organisation and the International Labour Organisation. They describe the issues facing managers and employees in organisations and recount some examples of best practice in nations such as Finland and Canada. Harnois and Gabriel (2000) also state that the UK's Department of health and the Confederation of British Industry have estimated that $15-30 \%$ of workers will experience some form of mental health issues over their working lives. Stevenson and Farmer (2017) were commissioned by the UK's Health and Safety Executive to conduct a review into the role employers can play to better support individuals with mental health conditions in the workplace. Their 'Thriving at Work' report proposes a set of six mental health core standards:

- Produce, implement and communicate a mental health at work plan;

- Develop mental health awareness among employees;

- Encourage open conversations about mental health and the support available when employees are struggling;

- Provide employees with good working conditions and ensure they have a healthy work life balance and opportunities for development;

- Promote effective people management through line managers and supervisors;

- Routinely monitor employee mental health and wellbeing.

Despite health and safety at work legislation, individuals may be faced with regular traumatic incidents placing them at risk of developing poor mental health including depression, anxiety and post-traumatic stress disorder. Reger, Bourassa, Smolenski, Buck, Norr et al. (2019) demonstrated the importance of lifetime exposure to trauma among U.S. combat veterans and highlighted the need to account for a variety of traumatic experiences across an individual's lifespan.

The impact of trauma is varied and depends upon a wide range of variables which includes the intensity of the experience and perceived level of threat, an individual's resilience and coping responses and previous levels of trauma (Tolin and Foa, 2006). However, many victims of violent crime report symptoms such as stomach distress, rapid heart rate, high blood pressure, headaches, diminished or increased appetite, insomnia, body tension or hyperventilation and some exists that long -terms exposure to violence -related stress can 
also lead to psychological changes like disruption of tissue function (Perrot and Kelloway, 2006: Mayhew 2000; European Agency for safety and Health at Work, 2010). Kilpatrick et al. (2013) suggested that most security guards who experienced a violent act are able to cope with the trauma. However, the methods employed to cope are not reported. Studies which relate to the consequences of physical workplace violence and emotional wellbeing on security professionals are very rare. According to Vanheule et al. (2008) studies show that 2 in 10 security professionals suffer from burnout as a result of experiencing a "critical incident" at work which according to them is defined as "a confrontation that is sufficiently disturbing to overwhelm or threaten to overwhelm the individual's usual method of coping" (Alexander \& Klein, 2001, p76). Similarly, Leino et al. (2011), observed a strong relationship between physically violent acts (i.e. hitting or kicking, and threats of assault with a deadly weapon) and distress among a sample of 1007 security professionals. The current study aimed to explore: i) what type of trauma security professionals experienced; ii) what impact this may have had on their mental health and wellbeing; iii) what coping strategies have they utilized to manage any distress they have experienced.

\section{Security Operatives and Masculinity}

Given the psychology-related nature of the research, it is not deemed out of place to briefly address the concept of masculinity in the security operative workforce that is so maledominated in any depth. Indeed $91 \%$ of licence holders are male and only $9 \%$ female in the UK (SIA, 2017). Kerfoot and Knights (1996, p 86) refer to masculinity as "the socially generated consensus of what it means to be a man or to display such behaviour." Connell and Messerschmidt (2005, p834) discuss the concept of hegemonic masculinity and describe how it has helped "in understanding not only men's exposure to risk but also men's difficulties in responding to disability and injury." Koeppen $(2019$, p22) claims that "research suggests that hegemonic masculinity can limit men's access to and expression of vulnerable feelings." This is an important observation given the male dominance of the industry, the sample for this research and the findings that will be shortly set out. Before these findings are explored, the methodology of the paper will be outlined.

\section{Methodology}

Design 
The current study utilized a mixed methods design to explore the experiences of security personnel. The areas of interest included work related trauma, coping strategies, resilience, mental health and wellbeing, and support offered.

\section{Participants}

The researchers secured 754 participants from an online survey circulated by the GMB trade union to its members. For security operatives wishing to join a trade union the GMB is the main choice in the UK. The GMB tends to draw its members from large companies such as G4S where there are recognition agreements. It is reluctant to publish membership rates but membership is thought to be in the tens of thousands. Therefore the sample for this study is biased towards larger companies and trade union members. From the quantitative survey circulated, a total of 227 consented to be contacted for interview, which was considered necessary to secure more depth to understanding the views and experience of respondents. Fifty individuals were chosen at random and 15 interviews were arranged from the sample. There was a gap of around 6 months from the survey complion to the contact for interviews, which may explain why only 15 agreed to participate. Ideally the researchers would have wanted to contact more of the 50 , but these were the only respondents who agreed to take part. No incentives were offered to participants.

\section{Materials}

Bristol Online Survey (now Online Survey) software was utilised for the original quantitative survey from which participants were subsequently identified. The physical equipment utilised for recording the interviews included a Sony handheld recording device with a USB port for uploading recordings with a two-way earpiece for recording telephone conversations.

The information sheet for participants informed potential participants about the purpose of the study, what it would entail and how the data would be used. Participants signed/clicked they agreed with the information sheet prior to taking part in the online survey. This was again completed when they took part in the qualitative element of the project to reiterate the participants right to omit questions and withdraw at any time. Due to the sensitive nature of the study, a debrief form including contact numbers for supporting organizations was distributed with all the survey responses and interviews. If any individual felt distressed by the interview, they were advised to seek help from their GP. Participants were also reminded 
of their right to withdraw their data at any time. The interview schedule was semi-structured exploring the experiences of trauma at work, coping strategies employed and what impact this may have had on their mental health. The questions were derived based on a range of research including that of Leino et al. (2011), Tolin and Foa, (2006) and Button (2007).

\section{Procedure}

The project followed a mixed methods approach of combining a quantitative survey with a question asking whether they would be interested in taking part in a qualitative interview about the same topic. As part of the online survey, questionnaires obtained information relating to the types of Security Industry Authority (SIA) licences held, the main form of employment and duration of service. Other areas explored included childhood trauma, work related trauma frequency, mental health and wellbeing and substance misuse. The survey questionnaire was constructed using Online Surveys and based on a hybrid of three separate mental health and wellbeing surveys:

1) The Warwick-Edinburgh Mental Wellbeing Scale (WEMWBS) (Tennant, Hiller, Fishwick, Platt, Joseph, Weich and Stewart-Brown, 2007);

2) The PTSD Checklist-Civilian Version (PCL-C) (Friedman, 2013); and

3) CAGE-AID as a screen for substance misuse (Couwenbergh, Van Der Gaag, Koeter, De Ruiter and Van den Brink, 2009).

Data investigating the mental health and wellbeing surveys will be explored in depth in a separate study to be published later. The researchers began with a pilot survey which was circulated by the SIA to three security companies in two cites in South East England and 19 completed surveys were returned (these returns are not included in the data used for the findings to be discussed). Based on the results of the pilot survey, the survey questionnaire was refined and then circulated more widely to a non-probability purposive sample of security operatives in the UK by the GMB trade union via its network of union representatives in the UK's private security industry. The survey was completed by 754 security operatives, of whom $19 \%$ identified as military veterans.

The interviews began by the researchers developing trust with the participants and this was achieved by conducting the telephone interviews at an agreed time and with the use of a 
participant information sheet and consent form. Participants were reminded of their right to omit questions, take a break and withdraw at any time. A debrief form was offered once the interview as completed detailing the purpose of the study and supporting organizations if they felt distressed by the current study. They were thanked for their participation and offered a summary of results once the study was complete. Once the data was transcribed verbatim, it was anonymised with participants given a pseudonym to protect their anonymity. All recordings were subsequently deleted once transcription was completed. Data was held securely on password protected devices at all times.

\section{Ethical Considerations}

The current project received ethical approval from the relevant university committee. Ethical considerations involved being mindful of the possible distress that individuals may encounter as part of the study which was minimized by providing a debrief form with supporting organizations and reminding participants they may withdraw at any time or omit any question. Data was held securely in line with the Data Protection Act (2018) through using password protected devices. All transcripts were anonymised and any correspondence were deleted once interviews were arranged. Access to the transcripts and data was restricted to the authors only.

\section{Findings}

The demographics of the respondents to the survey questionnaire can be found in table 1 and for the interviewees in table 2. All interviewees have been given false names to protect their identities. They are all white males, save for Paul who is black of African origin. Their ages range from 18 (Colin) to 57 (Brian). Two of them work in CCTV monitoring (Brian and Dave), two in retail (Mark and Paul) while Martin works as a cash-in-transit courier and Trevor works in crowd management. All the others are security guards or door supervisors

\section{Demographics}

\begin{tabular}{|l|l|l|}
\hline Ethnic Group & $\begin{array}{l}\text { Numbe } \\
\text { r }\end{array}$ & $\begin{array}{l}\text { Percentag } \\
\text { e }\end{array}$ \\
\hline White & 644 & $88 \%$ \\
\hline Mixed / multiple ethnic groups & 2 & $0.3 \%$ \\
\hline Asian / Asian British & 30 & $4.1 \%$ \\
\hline
\end{tabular}




\begin{tabular}{|l|l|l|} 
Black / African / Caribbean / Black British & 44 & $6 \%$ \\
\hline Other ethnic group & 12 & $1.6 \%$ \\
\hline
\end{tabular}

Table 1: Survey respondents' demographics

\begin{tabular}{|l|l|l|l|l|}
\hline Name & Age & Ethnicity & $\begin{array}{l}\text { Years in } \\
\text { Security }\end{array}$ & Role \\
\hline Adrian & 38 & White & 3 & Door supervisor \\
\hline Alan & 44 & White & 20 & Security guard \\
\hline Brian & 57 & White & 15 & CCTV monitoring \\
\hline Chris & 34 & White & 15 & Construction site security guard \\
\hline Colin & 18 & White & 2 & Door supervisor \\
\hline Dave & 46 & White & 2 & CCTV monitoring \\
\hline Ed & 40 & White & 14 & Door supervisor \\
\hline Harry & 55 & White & 8 & Job Centre security guard \\
\hline Luke & 42 & White & 12 & Door supervisor \\
\hline Mark & 40 & White & 22 & Retail \\
\hline Martin & 43 & White & 15 & Cash in Transit \\
\hline Paul & 33 & Black & 7 & Retail \\
\hline Richard & 56 & White & 5 & Door supervisor \\
\hline Stan & 55 & White & 8 & Job Centre \\
\hline Trevor & 45 & White & 20 & Crowd Management \\
\hline Victor & 39 & White & 12 & Security guard \\
\hline
\end{tabular}

Table 2: Interviewees' Demographics

Table 3 shows a summary of the codes and frequency that they were manifested in the aggregate of all of the interviews. The most frequent was a reference to security operatives exhibiting signs of stress through their work, followed by references to workplace violence and employee welfare. The next most populous code was on issues of mental health. Evidence of some of these codes are presented below.

\begin{tabular}{|l|l|}
\hline Code & $\begin{array}{l}\text { Number } \\
\text { examples }\end{array}$ \\
\hline Coping mechanism & 7 \\
\hline Counselling & 1 \\
\hline Bullying & 1 \\
\hline Disputes & 2 \\
\hline Drug misuse & 1 \\
\hline Employee welfare & 19 \\
\hline Exploitation & 2 \\
\hline
\end{tabular}




\begin{tabular}{|l|l|}
$\begin{array}{l}\text { Perception of security } \\
\text { operatives }\end{array}$ & 7 \\
\hline Job satisfaction & 1 \\
\hline Mental health & 17 \\
\hline Motivation & 3 \\
\hline PTSD & 11 \\
\hline Stress & 31 \\
\hline Suicidal thoughts & 2 \\
\hline Trauma & 5 \\
\hline Unfair working practices & 5 \\
\hline Verbal abuse & 15 \\
\hline Working conditions & 14 \\
\hline Workplace violence & 28 \\
\hline
\end{tabular}

Table 3: Summary of the frequency of code mentions across all of the interviews

The findings of the research are set out below and include both the results of the quantitative survey as well as the interviews. Table 4 shows the age ranges of the security operatives, with the majority being aged between 51 and 60 .

\begin{tabular}{|c|c|c|c|c|c|}
\hline All Age Ranges & Count & Male Age Ranges & Count & Female Age Ranges & Count \\
\hline $20-25$ & 27 & $20-25$ & 21 & $20-25$ & 6 \\
\hline $26-30$ & 47 & $26-30$ & 39 & $26-30$ & 8 \\
\hline $31-35$ & 57 & $31-35$ & 49 & $31-35$ & 7 \\
\hline $36-40$ & 70 & $36-40$ & 59 & $36-40$ & 11 \\
\hline $41-45$ & 69 & $41-45$ & 57 & $41-45$ & 12 \\
\hline $46-50$ & 101 & $46-50$ & 77 & $46-50$ & 21 \\
\hline $51-55$ & 125 & $51-55$ & 93 & $51-55$ & 28 \\
\hline $56-60$ & 114 & $56-60$ & 102 & $56-60$ & 11 \\
\hline $61-65$ & 96 & $61-65$ & 85 & $61-65$ & 9 \\
\hline $66-70$ & 18 & $66-70$ & 17 & $66-70$ & 1 \\
\hline $71-75$ & 4 & $71-75$ & 4 & $71-75$ & 0 \\
\hline $76-80$ & 1 & $76-80$ & 1 & $76-80$ & 0 \\
\hline
\end{tabular}

Table 4: Age Ranges of the Security Operatives

Table 5 shows the proportion of male to female security operatives with males making up almost $85 \%$ of the sample population and females around $15 \%$. It was not felt that for the 
purposes of the study it was necessary to collect data on how security operatives identified in terms of gender, though future studies should perhaps consider this.

\begin{tabular}{|c|c|c|}
\hline Sex & Number & Percentage \\
\hline Male & 620 & $84.40 \%$ \\
\hline Female & 115 & $15.60 \%$ \\
\hline
\end{tabular}

Table 5: Proportion of Male and female security operatives

Table 6 contains details of the main licensing role of each of the security operatives. The largest proportion at $43 \%$ work as security guards and $26.4 \%$ work as door supervisors. However, it is fairly common for security guards secure a door supervisor licence which is more useful (they can work security at licensed premises too) and to supplement their income by working as door supervisors in the night time economy. Just under $20 \%$ did not hold an SIA licence and were likely to be working in non-regulated or exempt sectors such as in-house security.

\begin{tabular}{|c|c|c}
\hline Main Role & Number & Percentage \\
\hline Door supervisor & 195 & $26.4 \%$ \\
\hline Security guard & 318 & $43 \%$ \\
\hline Close protection & 15 & $2 \%$ \\
\hline Cash and valuables in transit & 98 & $13.2 \%$ \\
\hline Public space surveillance & 139 & $18.8 \%$ \\
\hline Key holding & 15 & $2 \%$ \\
\hline I do not hold an SIA licence & 145 & $19.6 \%$
\end{tabular}

Table 6: The Main Licensing Role of the Security Operatives

\section{Verbal abuse}

Table 7 shows the survey results for security operatives' experience of the frequency of suffering verbal abuse in the workplace. Almost a quarter of the sample population suffered verbal abuse every day in the workplace and a similar proportion endured such abuse at least once a week. Only $16.1 \%$ of respondents reported never having been verbally abused in the workplace. In the interviews, verbal abuse in the workplace was mentioned 15 times. 


\begin{tabular}{|c|c|c|}
\hline Verbal Abuse & Number & Percentage \\
\hline Never & 118 & $16.1 \%$ \\
\hline Once a year & 142 & $19.3 \%$ \\
\hline Once a month & 146 & $19.9 \%$ \\
\hline Once a week & 164 & $22.3 \%$ \\
\hline Every day & 165 & $22.4 \%$ \\
\hline
\end{tabular}

Table 7: Security Operatives' Experience of Frequency of Verbal Abuse

Examples of verbal abuse from the interviews include Luke who states that:

"Verbal assaults, I think that's 90 per cent of what I'm having to deal with, at the minute, is verbal assaults."

Similarly, Harry's every day experience of verbal abuse working in a Job Centre in the Department of Work and Pensions shows what he has to put up with:

"To be honest, I don't mean to use foul language, but if you're not called a w**ker at least once a day, then really you're not considered by the Department of Work and Pensions, to do your job, because technically you are there to take all the abuse that they say, on their big signs, that you see in all the job centres, our staff will not tolerate."

Furthermore, Richard shares his experience of verbal and physical abuse:

"I've been hit and spat at and called names."

Victor's experience of verbal abuse included racist undertones which caused him upset:

"Just the gentleman within McDonald's, saying I was racist, that upset me more than any physical abuse because it's stating something that I'm not."

\section{Threats of violence}

Table 8 shows the survey results for the proportion of security operatives who had suffered threats of violence. Over $10 \%$ of the sample population reported threats of violence on a 
daily basis in the workplace and $15.4 \%$ reported threats of violence in the workplace at least once a week.

\begin{tabular}{|c|c|c|}
\hline Threats of violence & Number & Percentage \\
\hline Never & 244 & $33.6 \%$ \\
\hline Once a year & 163 & $22.5 \%$ \\
\hline Once a month & 130 & $17.9 \%$ \\
\hline Once a week & 112 & $15.4 \%$ \\
\hline Every day & 77 & $10.6 \%$ \\
\hline
\end{tabular}

Table 8: Security Operatives Experience of Frequency of Threats of Violence

Examples of threats of violence include that of Ed, a door supervisor:

"You're standing in front of someone who is right in your face, like nose to nose, shouting, screaming and swearing, threatening violence."

He goes on to describe an incident in which he needed to be helped by a colleague when they were trying to evict a violent nightclubber:

"He was huge and he was very heavy and very strong and it had the potential to be a very dangerous situation with all the glass and everything that was around."

Richard's experience is all too common a phenomenon in the night time economy:

"You just get people who just want to go out for a fight, causing trouble all night. Just putting up with that really, bad."

Harry describes the twin issues of dealing with threats of violence and any potential consequences:

"And not only have you got the issue of having to deal with the person who's wielding some sharp implement, you've also got to deal with the aftermath of if there is anything to deal with, the mental health issues, the stress, the anxiety."

Victor describes a situation he had to endure at a music festival:

"I've had a glass thrown at me, by a customer at a festival. They got quite abusive, swore at me and my colleagues." 
Victor goes on to comment that:

"Sometimes you get hurt, sometimes you'll get punched, but sometimes they say it's part of the job but it's not part of the job, you've got to try and get those people out, to prevent that."

Chris describes how sometimes the violence comes from their own side:

"You're on a building site, like for example, just my last job there, and you're having to tackle a violent and aggressive member of staff, a security guard, who is more of a risk to you than potentially a thief or an intruder. Now that's crazy."

\section{Workplace violence}

Tables 9 and 10 describe security operatives' experiences of minor and major physical assaults in the workplace. Over $20 \%$ and $10 \%$ respectively reported suffering a minor or major physical assault in the workplace once a year. Almost $10 \%$ reported a minor physical assault at least once a month. In the interviews, workplace violence was mentioned 28 times.

Such assaults as those endured by Alan:

"The thing is that if I go into a bank and start spitting at somebody, l'd get arrested, but in the Job Centre it's just part and parcel of, oh, you're a security guard, you have to absorb it."

This is echoed by Harry who was spat at in the face by a young woman:

"The Job Centre said, oh she's got to come back in half an hour, she's got another appointment. I said, she's just spat in my face. Oh well, she needs to come back to the appointment. It's alright, it's only spit, they said." 


\begin{tabular}{|c|c|c|}
\hline $\begin{array}{c}\text { Minor physical assault (no } \\
\text { medical treatment required) }\end{array}$ & Number & Percentage \\
\hline Never & 469 & $64.3 \%$ \\
\hline Once a year & 155 & $21.3 \%$ \\
\hline Once a month & 69 & $6.5 \%$ \\
\hline Once a week & 28 & $3.8 \%$ \\
\hline Every day & 8 & $1.1 \%$ \\
\hline
\end{tabular}

Table 9: Security Operatives' Experience of Frequency of Minor Physical Assault

\begin{tabular}{|c|c|c|}
\hline $\begin{array}{c}\text { Major physical assault (medical } \\
\text { treatment required) }\end{array}$ & Number & Percentage \\
\hline Never & 614 & $84.7 \%$ \\
\hline Once a year & 85 & $11.7 \%$ \\
\hline Once a month & 17 & $2.3 \%$ \\
\hline Once a week & 6 & $0.8 \%$ \\
\hline Every day & 3 & $0.4 \%$ \\
\hline
\end{tabular}

Table 10: Security Operatives' Experience of Frequency of Major Physical Assault

Adrian describes some of the workplace violence he has endured:

"I've been bottled, I've been slashed with bottles, that's the negative side of it."

Harry describes how women in Job Centres can also be violent:

"And women are just as bad. People say it's men in job centres, I've seen women come in, and left hook each other, literally left hook each other over something like you're sleeping with my ex-boyfriend and they happen to bump into them in the job centre."

He goes on to describe a violent incident with a man in the same Job Centre:

"Suddenly he just picks up a keyboard, rips it from this woman's desk, picks it up, and wraps it around this guard's face, and then throws the computer across the room."

He goes on: 
"I know a guard who's chased a shoplifter out at the request of the manager, 'cause the guy had nicked a twenty quid bottle of Scotch, he got outside, turned the corner, and had his head kicked in by four guys."

Harry recalled some other incidents relating to colleagues:

"I had an incident in [name of town] okay, a guy was assaulted at the back. Now when you come into the back of [name of town] Job Centre, there's a ramp where disabled people come in okay? He was dealing with an incident there, and the guy assaulted him on the ramp, okay? Punched him in the face, assaulted him, and then just left."

He described another:

"I've got another one where the guy was pushed down the stairs, and they said it was his fault, because he shouldn't have had an altercation at the top of the stairs. But he was walking a guy out, the guy just turned around, grabbed hold of his lapels and threw him down the stairs."

Luke was punched:

"So I told them again politely, you know, would you mind leaving. They went to leave out the back so I asked them to leave out the front and then that's when I was punched."

Mark had become normalised to dangerous incidents:

“The only thing I haven't dealt with is murder. I've dealt with attempted murder, I've dealt with rape, I've given CPR four times, so I've had quite a wide range of incidents. Violent incidents, a lot of violent shop lifters."

Martin who worked in CVT had experienced several attacks:

"I was in the London area for many years and have witnessed and been subject to some attacks, because we deliver and collect cash and valuables."

He went on:

"And also dealt with a lot of people who, some of them had been attacked up to 15 times, and then in my role as a rep, have witnessed many attacks." 
He noted the consequences of these attacks on staff:

"For the people that have suffered attacks, having seen them, there comes a point when they just change, when that one was one too many, and they're never the same as they were."

Adrian also described the extensive violence he had seen and suffered:

"I've had guns pulled on me, I've seen someone get their arm cut off on front of me, whilst working, I've seen someone get stabbed, my colleagues have been stabbed."

These incidents ultimately have an impact on security operatives in terms of their mental health and the next section will examine some of these key findings.

\section{Mental health / PTSD}

The results of the PTSD Checklist-Civilian Version (PCL-C) (Bliese, Adler and Hoge, 2007) used in the survey questionnaire can be interpreted in different ways. According to Friedman (2013), for an individual to have a probable diagnosis of PTSD, then sufficient criteria must at least moderately be met in each of the four symptom groups among the 20 questions. This requires that answers given to one or more symptoms from questions 1 to 5 , either question 6 or 7 , two or more from questions 8 to 14 , and two or more from questions 15 to 20 must be either "moderately", "quite a bit" or "extremely" on the 5-point Likert scale. Murphy, Ross, Ashwick, Armour and Busuttil (2017) recommend that a diagnosis for PTSD using the DSM-5 checklist would require an individual to score 33 or higher. In this research the cut off point for a PTSD diagnosis was set at 33 . Table 7 shows that $39.3 \%$ of respondents are showing the full diagnostic criteria for DSM-5 Post Traumatic Stress Disorder (Friedman, 2013) with PTSD scores of 33 and above ( $N=285)$. 


\begin{tabular}{|l|r|r|r|r|}
\hline & \multicolumn{1}{|l|}{ Frequency } & Percent & \multicolumn{2}{|l|}{$\begin{array}{l}\text { Valid Percent } \\
\text { Percent }\end{array}$} \\
\hline Valid 00 & 441 & 60.7 & 60.7 & 60.7 \\
\hline 1.00 & 285 & 39.3 & 39.3 & 100.0 \\
\hline Total & 726 & 100.0 & 100.0 & \\
\hline
\end{tabular}

Table 11: PTSD Scores of respondents.

There were various references to PTSD and mental health in the interviews and some of them are set out below. From Dave's perspective, he was concerned that even a short period of time serving in frontline policing would suffer from mental health issues:

"I'm convinced that anybody who's spent more than a few years as a uniformed frontline police officer, a response officer, will have some degree or other of PTSD."

For Ed the coping mechanism of dealing with traumatic events which may be linked to PTSD is through talking therapies:

"Personally for me I tend to try and talk about it with others - and it helps if it's people that have had similar experiences as well - but it does, it has an effect; the fact that you can remember those traumatic events."

Harry describes how mental health is largely seen as a taboo subject among managers who at the same time do not know how to address it:

"The trouble with security guards is, one, they fail to mention anything that's a mental health issue, because they see it as a weakness, and the managers see it as a failing. And they don't understand it. Because they don't understand it, they're frightened of it, so they make a joke about it."

Furthermore, Harry highlights the issue thus:

"And that's where it falls down, because the guys that have the balls to come up and go well actually I've got mental health issues, whatever it may be, then his manager, instead of taking it seriously and helping him, laughs about it." 
In an effort at coping with the effects of an assault, Luke describes how he was unable to cope with its effects despite trying to manage the mental symptoms:

"That brawl I was telling you about, that...the impact afterwards, it went on. You know, I went out for a drink to try and relax and I was...I can't switch off, I couldn't switch off, I was just always looking."

He went on:

"This sort of stress has got, you know, has an impact on your quality of life, with, you know, based on activity levels, social life, relationships, mental health and all that sort of stuff."

He also describes how there is a total lack of support for mental health conditions within his company:

“There's no, sort of, there's no mental help for it. There's no offer of mental health, which there should be, you know",

and follows it up with a statement that:

"I think there should be more services to help door staff with, sort of, the verbal, physical and mental abuse."

From Martin's perspective, he was aggrieved that his employer decided not to send him on a mental health course owing to his union membership:

"I recently should have been on a mental health course, like a mental health first aider's course, and they (the company) didn't feel it was relevant to the role, and put a block on that."

Martin goes on to state that:

"I don't feel that the managers are suitably trained in dealing with people who are truly mentally ill."

Finally, Martin states that:

"I've seen most of the guys that came out of it with PTSD, homelessness and all that kind of thing. There was...when I was getting really, really stressed out, because the 
government per se is not helping at all, and we were not priority on the Council list and all that, so even getting accommodation was difficult."

\section{Discussion}

The key findings in the research indicate that serious underlying issues exists in the private security sector in terms of the degree of PTSD that is prevalent among the workforce. With almost $40 \%$ of those surveyed in the research exhibiting symptoms of PTSD with varying degrees of severity and from the interviews a clear message that the issue of PTSD is not currently being taken seriously by security managers, there is an emerging picture of a failure by the security industry to address the issues of poor mental health and wellbeing among security operatives. With managers currently ignoring or downplaying issues of poor mental health and wellbeing among their workforce, it is unlikely that much will change without a significant input from public policy makers to redress the issue. More research is required on the level of support currently provided by security companies and to explore how the provision of mental health support can be improved.

With regards to PTSD, the reaction by managers to Harry and Martin's experiences of a lack of mental health support and the inability of such managers to comprehend the scale of the problem and the need for a solution may be compounded by security operatives' inherent masculinity where their desire to seek help may be viewed as a weakness. This is also reflected in the work of Connell and Messerschmidt (2005) and Koeppen (2019).

In terms of threats of violence and actual violence encountered in the workplace both the survey results and the qualitative data gained from the interviews add to the findings of much of the literature addressed earlier, specifically in Leino (2013), Leino et al. (2011), Button (2007) and Manzo (2006). The quantitative findings in this study indicate that $64.6 \%$ of UK security operatives endured verbal abuse at least once a month. This contrasts with Leino's (2013) study where the figure was 39\%. Similarly, the figure for UK security operatives who endured threats of violence at least once a month was $43.9 \%$ and the corresponding figure for the Finnish study was $19 \%$. However, when comparing actual physical violence endured by the UK security operatives at least once a month the figure in this study is $14.9 \%$ and in the Finnish study it is $15 \%$. This is interesting given the comparable sizes of each study (UK: 
$N=754$; Finland: $N=1010$ ). Further research outside of the UK and Finland could investigate the extent to which this may be a trend.

The qualitative findings indicate a high prevalence of workplace violence in the security industry with incidents including operatives witnessing or being punched (Victor), spat at (Richard and Harry), beaten up (Harry), knifed, pushed down the stairs (Harry) and had guns trained on them (Adrian). These serve to have a significant impact on the mental health of security operatives. Some of the coping mechanisms employed by security operatives, such as reported by Luke, included alcohol use, as confirmed by Reynolds et al. (2005) but in his case there seemed to be little respite due to his hyperarousal. Debell et al. (2014) report on comorbidity between PTSD and alcohol misuse and there is scope to investigate this phenomenon in more detail in future research.

One key finding of the research is the lack of support provided by security companies to their employees in terms of the provision of mental health services. This must change and more research is required on what the security industry as a whole must do to address this issue before it becomes a larger societal issue with added pressure on limited mental health and wellbeing services provided by the National Health Service.

\section{Conclusion}

This mixed methods study has found that security operatives endure both verbal and physical threats during the course of their work. They also endure physical attacks in a variety of work places from the night time economy to retail outlets to job centres. These attacks have left many of the security operatives suffering from poor mental health and wellbeing and in a surprisingly large amount of cases (39.3\%), diagnosed with post-traumatic stress disorder.

This is the largest study of mental health and wellbeing among security operatives in the UK to date and while it has merely scratched the surface in terms of uncovering the scale and nature of the problem, much further research needs to be conducted in order to assess the degree of support that security companies are supplying to their employees both currently 
and the level that may be required in the future. Furthermore, there is scope to make recommendations to policy makers about potential solutions to the problem. 


\section{References}

American Psychiatric Association. (2013). Diagnostic and statistical manual of mental disorders (5th ed.). Arlington, VA

Alexander, D., \& Klein, S. (2001). Ambulance personnel and critical incidents: Impact of accident and emergency work on mental health and emotional well-being. British Journal of Psychiatry, 178(1), 76-81

Busby, R. N. (2015) "Incidence and Cost of Nurse Workplace Violence Perpetrated by Hospital patients or Patient Visitors" Journal of Emergency Nursing 41(1):5-8

Button, M. (2007) Security officers and Policing: Powers Culture and Control in the Governance of Private Space, Aldershot, UK, Burlington, USA: Ashgate Publishing Limited

Button, M. and Park, H. (2009) "Security officers and the policng of private space in South Korea: profile, powers and occupational hazards" Policing \& Society 19(3):247-262

Button, M. (2019) "Private Policing". $2^{\text {nd }}$ Edition. Abingdon: Routledge.

Claase-Schutte, C. and Pillay, K. (2004) "Private security officers as victims of trauma and stress : the South African experience and initiatives to manage it." Acta Criminologica: Southern African Journal of Criminology, Vol. 17, No. 1, pp. 121-128

Couwenbergh, C., Van Der Gaag, R., Koeter, M., De Ruiter, C. and Van den Brink, W. (2009) Screening for Substance Abuse Among Adolescents Validity of the CAGE-AID in Youth Mental Health Care, Substance Use \& Misuse, 44:6, 823-834

Connell, R. and Messerschmidt, J. (2005). Hegemonic Masculinity: Rethinking the Concept. Gender \& Society, 19(6), 829-859.

Crawford, A., Lister, S., Blackburn, S. and Burnett, J. (2005) Plural Policing. Bristol: The Policy Press.

De Boer, E. M., Bakker, A. B., Syroit, J.E>, Schaufeli, W.B. (2002) "Unfairness at work as a predictor of absenteeism" Journal of Organisational Behaviour 23(2):181-197

Debell, F., Fear, N.T., Head, M., Batt-Rawden, S., Greenberg, N., Wessely, S. and Goodwin, L. 2014. Social Psychiatry and Psychiatric Epidemiology Vol. 49, pp. 1401-1425

Doyle, M.M., Murphy, J. \& Shevlin, M. J "Competing Factor Models of Child and Adolescent Psychopathology" Journal of Abnormal Child Psychology (2016) 44: 1559.

Ehlers, A. and Clark, D. (2000) "A cognitive model of posttraumatic stress disorder", Behaviour Research and Therapy, Volume 38, Issue 4, Pp 319-345

European Agency for Safety and Health at Work (2010) Workplace Violence and Harassment: A European picture, Luxemborg: Publications Office for the European Union 
Ferguson, P., Prenzler, T., Sarre, R., and De Caires, B. (2011) Police and security officer experiences of occupational violence and injury in Australia. International Journal of Police Science and Management, 13(3), 223-233.

Friedman, M.J. (2013). Finalizing PTSD in DSM-5: getting here from there and where to go next. Journal of traumatic stress, 26 5, 548-56.

Gates, D.M, Gillespie, G. L. Succop, P. (2011) “Violence Against Nurses and its Impact on Stress and Productivity" Nursing Economics 29(2):59-67

Green, B. (2004) "Post-traumatic stress disorder in UK police officers", Current Medical Research and Opinion, 20:1, 101-105

The Guardian (2019) Three charged with murder in stabbing of London security guard. Retrieved from https://www.theguardian.com/uk-news/2019/jan/29/tudor-simionovsecurity-guard-stabbing-three-charged-murder-new-years-eve-party-park-lane-london

Harnois, G. and Gabriel, P. (2000) "Mental health at work: impact, issues and good practices", World Health Organisation, Geneva

Health and Safety Executive (2015) Violence at Work, http://www.hse.gov.uk/statictics/causinj/violence/index.htm (accessed 20th December 2018)

Healy, S., \& Tyrrell, M. (2011). Stress in emergency departments: experiences of nurses and doctors. Emergency Nurse, 19(4), 31-37.

Hobbs, D., Hadfield, P., Lister, S. and Winlow, S. (2005) Bouncers: Violence and Governance in the Night-time Economy. Oxford: Oxford University Press.

Hobbs, D., O'Brien, K., and Westmarland, L. (2007) Connecting the gendered door: Women, violence and doorwork. The British Journal of Sociology, 58(1), 21-38.

Hosseinikia, S. H., Zarei, S., Kalyani, M.N. and Tahamtan, S. (2018) "A Cross- Sectional Multicenter Study of Workplace Violence against Prehospital Emergency Technician's Emergency Medicine International 2018(n.i), Article ID7835676 http://doi.org/10.1155/2018/7835676

Jenkins, E.L, Fisher, B.S., Hartley, D. (2012) "Safe and secure at Work? Findings from the 2002 Workplace Risk Supplement" Work 42 (1): 57-66

Jones, T. and Newburn, T. (1998) Private Security and Public Policing. Oxford: Clarendon Press. Kessler, R., Sonnega, A., Bromet, E., Hughes, M., and Nelson, C. (1995) “Posttraumatic Stress Disorder in the National Comorbidity Survey" Arch Gen Psychiatry. 52(12):1048-1060. 
Kilpatrick, D. G., Resnick, H. S., Milanak, M. E., Miller, M. W., Keyes, K. M. and Friedman, M. J. (2013), National Estimates of Exposure to Traumatic Events and PTSD Prevalence Using DSMIV and DSM-5 Criteria. Journal of Traumatic Stress, 26: 537-547

Kerfoot, D. and Knights, D. (1998). "Managing Masculinity in Contemporary Organizational Life: A Managerial Project". Organization, 5(1), 7-26.

Koeppen, B. (2019) "Retail security guards' experiences of and reactions to workplace violence." Unpublished PhD thesis, University of Leicester

Kvas, A., Sejak, J. (2014) "Unreported Workplace Violence in Nursing" International Nursing Review 61(3):344-351

Leino, T. (2013) Work-related violence and its association with psychological health: A study of Finnish police patrol officers and security guards, People and Work Research Report 98, Helsinki, Finland: Finish Institute of Occupational Health.

Leino, T. M., Selin, R., Summala, H. and Virtanen, M. (2011), "Violence and psychological distress among police officers and security guards", Occupational Medicine, 61(6), 400-406

Lister, S., Hobbs, D., Hall, S., \& Winlow, S. (2000). "Violence in the night-time economy; bouncers: The reporting, recording and prosecution of assaults". Policing and Society. 10(4), 383-402.

Lofstrand, C., Loftus, B. and Loader, I. (2016). "Doing dirty work: Stigma and esteem in the private security industry". European Journal of Criminology. 13(3). 297-314.

Messman-Moore, T. L., \& Long, P. J. (2000). Child Sexual Abuse and Revictimization in the Form of Adult Sexual Abuse, Adult Physical Abuse, and Adult Psychological Maltreatment. Journal of Interpersonal Violence, 15(5), 489-502.

Manzo, J. (2006). "You Can't Rent a Cop": Mall Security Officers' Management of a "Stigmatized" Occupation. Security journal, 19(3), 196-210.

Murphy, D., Ross, J., Ashwick, R., Armour, C. and Busuttil, W. (2017) "Exploring optimum cutoff scores to screen for probable posttraumatic stress disorder within a sample of UK treatment-seeking veterans", European Journal of Psychotraumatology, 8:1

Nalla, M. K., and Cobbina, J. E. (2017) Environmental Factors and Job Satisfaction: The Case of Private Security Guards. Security Journal, 30(1), 215-226.

Nalla, M. K., Lim, S. L. S., and Demirkol, I. C. (2015) The Relationship Between Goal Difficulty, Goal Specificity, Rewards and Job Satisfaction: A study of Singapore Security Guards. Security Journal, 28(4), 392-409.

Nalla, M. K., Paek, S. Y., and Lim, S. S. (2017) The Influence of Organizational and Environmental Factors on Job Satisfaction Among Security Guards In Singapore. Australian and New Zealand Journal of Criminology, 50(4), 548-565. 
Nienhaus, A. Drechsel-Schlund, C., Schambortski, A., Schablon, H.(2016) "Violence and Discrimination at Work- Health Consequences and Settings Specific Approaches for Prevention and Rehabilitation" Bundesgesundheitsblatt 59 (n.i.): 88-97

Noaks, L. (2000) Private Cops on the Block: A Review of the Role of Private Security in Residential Communities. Policing and Society, 10 (2) 143-161.

Perrott, S. and Kelloway, E.K. (2006) "Workplace Violence in the Police" Sage Publications, Thousand Oaks, CA

Porter, T., Bearn A., Percy A. (2015) Research on Violence Reduction Report, prepared for Security Industry Authority, London, UK: Security Industry Authority.

Prenzler, T., and Sarre, R. (2008) Protective security in Australia: Scandal, media images and reform. Journal of Policing, Intelligence and Counter Terrorism, 3(2), 23-37.

Reger, G., Bourassa, K., Smolenski, D., Buck, B. and Norr, A. (2019) "Lifetime trauma exposure among those with combat-related PTSD: Psychiatric risk among U.S. military personnel", Psychiatry Research, Vol. 278, Pp. 309-314

Reynolds, M., Mezey, G., Chapman, M., Wheeler, M., Drummond, C. and Baldacchino, A. 2005. "Co-morbid post-traumatic stress disorder in a substance misusing clinical population." Drug and Alcohol Dependence, Vol. 77, pp. 251-258

Rigakos, G., S. (2002) The New Parapolice. Toronto: University of Toronto Press.

Security Industry Authority (2017) Gender of Licence Holders. Retrieved from https://www.sia.homeoffice.gov.uk/Pages/info-responses.aspx?FOI=4

Security Industry Authority (2019a) Licensing Statistics. Retrieved from https://www.sia.homeoffice.gov.uk/pages/licensing-stats.aspx

Security Industry Authority (2019b) 'Safer Nights Out - Poster 3'. Retrieved from https://www.sia.homeoffice.gov.uk/pages/publications.aspx?category=Safer+Nights+Out

Stevenson, D, Farmer, P 2017, Thriving at work: the Stevenson/Farmer review of mental health and employers, Department for Work and Pensions and Department of Health, London, viewed 24 Oct 2019, <https://www.gov.uk/government/publications/thriving-atwork-a-review-of-mental-health-and-employers.

Sweet, A.M (2017) Workplace violence: A comprehensive look at OSHA recordkeeping, unpublished Master's Thesis, Department of Technology Systems, East Carolina University

Tennant, R., Hiller, L., Fishwick, R., Platt, S., Joseph, S., Weich, S., Parkinson, J. Secker, J. and Stewart-Brown, S. (2007) "The Warwick-Edinburgh Mental Well-being Scale (WEMWBS): development and UK validation". Health and Quality of Life Outcomes 5, 63 
Tolin, D. F., \& Foa, E. B. (2006). Sex differences in trauma and posttraumatic stress disorder: A quantitative review of 25 years of research. Psychological Bulletin, 132, 959-992.

Vanheule, S., Declercq, F., Meganck, R., Desment, M. (2008) "Burnout critical incidents and social support in security guards" Stress and Health 24(2):137-141

Vezyridis, P., Samoutis, A., Mavrikiou, P.M.(2014) "Workplace Violence against Clinicians in Cypriot Emergency Departments: A National Questionnaire Survey" Journal of Clinical Nursing 24 (9-10):1210-1222'

Waddington, P.A.J., Badger, D., Bull, R (2005a) 'Appraising the Inclusive Definition of Workplace "Violence"' British Journal of Criminology 45(2): 141-164

Waddington, P.A.J., Badger, D., Bull, R (2005b) The Violent Workplace, Cullompton, UK: Wilan Publishing

Wagner, D., Heinrichs, M. and Ehlert, U. (1998) "Prevalence of Symptoms of Posttraumatic Stress Disorder in German Professional Firefighters" American Journal of Psychiatry, 155:12, 1727-1732

Wakefield , A. (2003) Selling Security - the Private Policing of Public Space. Cullompton, UK: Willan.

White, A. (2012). The new political economy of private security. Theoretical Criminology, 16 (1), 85-101.

Winlow, S. (2001). Badfellas: Crime, tradition and new masculinities. Bloomsbury Academic. 